\title{
Title
}

Enzymatic activity and conformational and morphological studies of four commercial lipases treated with supercritical carbon dioxide

\section{Author names}

Melgosa, R. (rmgomez@ubu.es)

Sanz, M. T. (tersanz@ubu.es)

Beltrán, S. (beltran@ubu.es)

Solaesa, A. G. (agsolaesa@ubu.es)

Bucio, S.L. (sbl0017@alu.ubu.es)

\section{Affiliation}

Department of Biotechnology and Food Science (Chemical Engineering Section), University of Burgos, 09001 Burgos, Spain

\section{Corresponding author}

Sanz, M. Teresa

Department of Biotechnology and Food Science (Chemical Engineering Section), University of Burgos, Pza. Misael Bañuelos s/n 09001 Burgos, Spain Tel.: +0034947258810.

Fax: +0034 947258831.

E-mail address: tersanz@ubu.es 


\begin{abstract}
This work investigates the effect of supercritical carbon dioxide $\left(\mathrm{SC}-\mathrm{CO}_{2}\right)$ treatment on four commercial lipases. The influence of experimental conditions: temperature (35 $\left.70{ }^{\circ} \mathrm{C}\right)$, pressure (100 - 250 bar), exposure time (60 - $\left.360 \mathrm{~min}\right)$ and depressurization cycles $(1-3)$ on the residual activity was studied. Activity enhancement was verified for free enzymes (Palatase $20000 \mathrm{~L}$ and Lipozyme CALB L) treated under mild conditions; while the highest temperature and pressure and the longest exposure time assayed led to activity losses. On the other hand, activity losses were observed in the enzyme activity of immobilized enzymes (Lipozyme RM IM and Lipozyme 435). Additional qualitative studies were performed: Fluorescence emission spectra showed changes in the conformational structure of both two free enzymes after $\mathrm{SC}-\mathrm{CO}_{2}$ treatment. Scanning electron micrographs showed morphological alterations in the immobilization supports of the treated enzymes; while infrared spectra did not show significant chemical modifications.
\end{abstract}

Keywords: Candida antarctica lipase B; Rhizomucor miehei lipase; Immobilized/free lipases; Enzyme activity; Supercritical carbon dioxide

\title{
1. Introduction
}

The utilization of enzymes as biocatalysts in many processes, either in their free or immobilized form, has become an increasingly important research field in recent years. Considerable attention has been paid to lipases, due to their high specificity in lipid biomodification and their selectivity towards fatty acid positions on the glycerol backbone [1]. 
Since the work of Zaks and Klibanov [2], organic solvents have been employed extensively in enzymatic reactions. However, they present serious environmental drawbacks and additional purification steps are needed to obtain the products of interest in a safe form. To cope with these issues, biochemical catalysis with lipases can be conducted in supercritical carbon dioxide $\left(\mathrm{SC}-\mathrm{CO}_{2}\right)$, a nontoxic, readily available, inexpensive, and easily removable solvent. In addition, the singular properties of supercritical fluids, such as liquid-like and tunable solvating power, and gas-like viscosity, diffusivity and surface tension, have a positive effect on the reaction performance [3]. Additionally, fractionation of the reaction products is possible by coupling a series of separators after the reactor vessel.

The study of enzyme deactivation or the improvement of enzyme stability is important in the implementation of biocatalysis in supercritical systems. Activity changes can be observed when enzymes are treated with $\mathrm{SC}-\mathrm{CO}_{2}$. In the case of immobilized enzymes, enzyme stability is related to many factors, including the source and nature of the enzyme, the characteristics of the support, and the immobilization method. Essential water in the enzyme microenvironment can be removed as a result of unfavorable partitioning between the support and the solvent, causing enzyme inactivation [4-6]. Other parameters during SC- $\mathrm{CO}_{2}$ treatment, such as pressure and temperature of the system, can also affect the enzyme activity. In high pressure-batch stirred reactors, exposure time, depressurization rate, and the number of pressurization/depressurization cycles are also important parameters that must be considered [7].

Free enzymes treated with SC-CO $\mathrm{CO}_{2}$ have been also studied. They are less expensive than immobilized enzymes and, since proteins are not soluble in $\mathrm{SC}-\mathrm{CO}_{2}$, free enzymes can be more easily separated from the reaction products than in conventional biocatalysis. 
Other reason is that the enzymatic activity can be improved when free enzymes are exposed to $\mathrm{SC}-\mathrm{CO}_{2}$ media. Although some researchers reported that certain free enzymes can be inactivated when exposed to $\mathrm{SC}-\mathrm{CO}_{2}$, mainly because of a $\mathrm{pH}$ decrease [8], other free enzymes have been reported to increase their activity after incubation in SC- $\mathrm{CO}_{2}$ (up to $760 \%$ residual activity, depending on the nature of the enzyme) [9]. Changes in the conformational structure due to enzyme residues and $\mathrm{SC}-\mathrm{CO}_{2}$ interactions [10-14], and/or extraction of water and impurities from the enzyme preparation [15] could explain this enzyme activity enhancement.

This work investigates the influence of temperature, pressure, exposure time and depressurization cycles on the activity of four commercial lipases treated with $\mathrm{SC}-\mathrm{CO}_{2}$ : two immobilized lipases (Lipozyme RM IM and Lipozyme 435); and two free lipases (Palatase $20000 \mathrm{~L}$ and Lipozyme CALB L). The aim of this study is to help to understand the effects of $\mathrm{SC}-\mathrm{CO}_{2}$ exposure on the activity of different commercial enzymes, as well as to help to select the best conditions to carry out further enzymatic reactions under $\mathrm{SC}-\mathrm{CO}_{2}$ medium. The analysis includes studies of the possible chemical, morphological and conformational modifications caused by SC-CO treatment. Fluorescence emission spectroscopy was applied in order to study the conformational changes that could have occurred in the structure of the free enzymes. Fourier transform-infrared spectroscopy (FT-IR) and scanning electron microscopy (SEM) were also used to evaluate the possible chemical and physical alterations in the immobilized enzymes, respectively. 


\section{Materials and Methods}

\subsection{Enzymes and chemicals}

Lipozyme RM IM and Palatase 20000 L were purchased from Sigma Aldrich (St. Louis, MO). Lipozyme 435 and Lipozyme CALB L were kindly provided by Novozymes (Bagsværd, Denmark).

Lipozyme RM IM is a lipase from Rhizomucor miehei, immobilized on Duolite A568 [16], a macro-porous hydrophilic granular weak base anion exchange resin, based on crosslinked phenol-formaldehyde polycondensate. The moisture content of Lipozyme RM IM was $3.8 \pm 0.2 \mathrm{~g} / 100 \mathrm{~g}$, determined by extraction with dry methanol during $24 \mathrm{~h}$ and further titration by Karl-Fischer method (Mitsubishi CA-20 automatic titrator). A similar value ( $3.3 \pm 0.2 \mathrm{~g} / 100 \mathrm{~g}$ ) was reported by Jenab et al. [17] by using a gravimetric method.

Lipozyme 435 is a recombinant lipase from Candida antarctica, expressed on Aspergillus niger, and adsorbed onto Lewatit VP OC 1600 [16], a macro-porous hydrophobic resin presented in spherical beads and based on cross-linked methacrylic esters. The moisture content of Lipozyme 435 was $0.7 \pm 0.2 \mathrm{~g} / 100 \mathrm{~g}$, determined by the same Karl-Fischer titration method.

Palatase 20000 L (free R. miehei lipase expressed on A. oryzae) and Lipozyme CALB L (free C. antarctica lipase expressed on A. niger) were provided in aqueous solution containing glycerol, sorbitol and other excipients and preservatives.

Carbon dioxide (99.9\%) was supplied by Carburos Metálicos S.A. (Spain). All other chemicals used were of analytical grade. 


\subsection{Enzyme treatment under $\mathrm{SC}-\mathrm{CO}_{2}$}

A schematic diagram of the experimental apparatus used in the enzyme treatment is depicted in Figure 1. Basically, it consists of a $\mathrm{CO}_{2}$ reservoir, a high pressure syringe pump with a pressure controller (ISCO $260 \mathrm{D}$ ) and 3 high pressure cells immersed in a thermostatic water bath.

In a typical experiment, the enzyme preparation was charged into the high pressure cell, which was then placed in the thermostatic water bath at the established temperature. Afterwards, the system was pressurized and maintained at constant temperature and pressure for a pre-established exposure time. Typically, the duration of the pressurization step was less than $0.5 \mathrm{~min}$ and accordingly was not included in the pressure holding time. Depressurization steps were performed at a constant decompression rate of $240 \mathrm{~kg} \mathrm{~m}^{-3} \mathrm{~min}^{-1}$. Experiments were done in a temperature and pressure range commonly used in enzymatic reactions: temperature (T) from 35 to $75^{\circ} \mathrm{C}$ and pressure (p) from 100 to 250 bar. Exposure time (t) was extended from 1 to $6 \mathrm{~h}$ for all enzymes. Additionally, several depressurization cycles (1 - 3) were carried out in the case of immobilized enzymes (see Table 1).

\subsection{Residual enzyme activity}

The enzyme activity of free enzymes after $\mathrm{SC}-\mathrm{CO}_{2}$ treatment was determined as the initial rate in the hydrolysis reaction of the olive oil triglycerides [12]. In a typical assay, $1 \mathrm{~mL}$ of enzyme preparation was added to the substrate, consisting on $4 \mathrm{~mL}$ of $10 \%$ homogenized olive oil and $5 \mathrm{~mL}$ of $50 \mathrm{mM}$ phosphate buffer $\mathrm{pH}=7.0$. The reaction was carried out at $50{ }^{\circ} \mathrm{C}$ for $15 \mathrm{~min}$. After incubation, $15 \mathrm{~mL}$ of a mixture of ethanol:acetone (1:1) was added to stop the reaction. Liberated fatty acids were titrated with KOH $0.1 \mathrm{~N}$ 
in ethanol. As a blank control, the reaction mixture without the enzyme was titrated in the same way.

The enzyme activity of immobilized enzymes after $\mathrm{SC}-\mathrm{CO}_{2}$ treatment was determined as the initial rate in the esterification reaction of lauric acid with propanol at a molar ratio of 3:1, $60 \%$ wt. hexane as reaction medium and enzyme concentration of $5 \%$ wt. based on the substrates. At the beginning of the reaction, samples containing the mixture of lauric acid and propanol were collected and the lauric acid content was determined by titration with $\mathrm{KOH} 0.1 \mathrm{~N}$ in ethanol by using an automatic titrator (Methrom Titrando 905). After the addition of the enzyme to the substrates, the mixture was kept at $50{ }^{\circ} \mathrm{C}$ for $15 \mathrm{~min}$. Then, the lauric acid consumption was determined by the same experimental procedure.

In all cases, residual activity was calculated as the relationship between the enzyme activity after $\mathrm{SC}-\mathrm{CO}_{2}$ exposure and the initial enzyme activity, expressed as percentage:

Residual activity $=\frac{\text { Activity after } \mathrm{SC}-\mathrm{CO}_{2} \text { treatment }}{\text { Activity of the untreated enzyme }} \cdot 100 \%$

All enzyme activity determinations were performed at least in triplicate.

\subsection{Enzyme assays}

The tertiary structure of the free enzymes was measured by fluorescence spectroscopy using a Varian Cary Eclipse spectrofluorimeter (Agilent Technologies) thermostated at $25{ }^{\circ} \mathrm{C}$. The excitation wavelength was $280 \mathrm{~nm}$, and the emission was read at $290-$ $450 \mathrm{~nm}$. All the spectra were scanned continuously with five replicates. All samples were diluted 10 times in pure water prior to analysis.

Infrared spectroscopy analyses were made to follow possible chemical alterations after exposure to $\mathrm{SC}-\mathrm{CO}_{2}$ since proteins absorb infrared wavelengths due to the peptide bond 
vibrations. Fourier transform-infrared spectroscopy (FT-IR) was performed in the 4000 - $400 \mathrm{~cm}^{-1}$ range using a Thermo-Nicolet Nexus 670 FT-IR spectrophotometer. Scanning electron microscopy (SEM) was performed to check possible changes in the morphological properties of the immobilized enzymes. Micrographs were obtained using a variable-pressure scanning electron microscope JEOL JSM-6460LV.

\section{Results and discussion}

\subsection{Free enzymes}

\subsubsection{Residual activity}

The experimental results obtained in the residual activity determination of the two free enzymes are compiled in Table 1 . The effect of pressure, temperature and exposure time is presented in Figures 2 a,b,c.

An increase in the residual enzyme activity of the two free lipases was observed when SC- $\mathrm{CO}_{2}$ treatments were performed at mild conditions (exp. 1, 2, 4, and 6). In any case, the increase in the enzyme activity after $\mathrm{SC}-\mathrm{CO}_{2}$ treatment is lower the higher the operating pressure and temperature, as well as the exposure time. Treatments at the highest pressure studied in this work (exp. 3) resulted in low activity losses of both two free enzymes (up to approximately $96 \%$ initial activity). Palatase 20000 L gained activity even after being exposed to high exposure time (exp 7) while slight activity loss was observed for Lipozyme CALB L.

In general, results obtained in Lipozyme CALB L residual activity determination are in agreement with those reported in the literature studying the same enzyme [12]. However, experimental conditions in the work by Liu et al. (6-10 MPa, 35-40 ${ }^{\circ} \mathrm{C}$ and 20-30-150 min) [12] promoted slightly lower activity enhancements than the observed 
in this study, suggesting that experimental conditions, i.e. pressure and temperature of the system, as well as exposure time, should not be neglected. The highest activity improvement was found when treating Palatase $20000 \mathrm{~L}$ at mild conditions (maximum of $134.8 \%$ initial activity at exp. 6). No references about the effect of the SC-CO treatment on Palatase $20000 \mathrm{~L}$ activity were found in the available literature.

The highest activity losses (86.3 for Palatase $20000 \mathrm{~L}$ and $80.9 \%$ initial activity for Lipozyme CALB L) were found at the highest temperature assayed (exp. 5). Therefore, they could be mainly attributed to thermal deactivation, possibly due to partial unfolding by breaking non-covalent interactions [13]. In any case, the residual activity of both free treated lipases remains above $80 \%$ at the highest temperature studied in this work (experience $5,70{ }^{\circ} \mathrm{C}$ ). The most thermostable lipase was Palatase $20000 \mathrm{~L}$ (86.3 \% initial activity at $70{ }^{\circ} \mathrm{C}$ ). Gießauf and Gamse [15] reported that thermal stability of free enzymes depends on many factors such as the presence of unstable impurities or stabilizers. Accordingly, Bauer et al. [18] related the activity loss of esterase EP10 from Burkholderia gladioli after SC-CO $\mathrm{CO}_{2}$ treatment at $75{ }^{\circ} \mathrm{C}$ to the presence of impurities in the enzyme preparation.

In the literature, it has been reported that $\mathrm{SC}-\mathrm{CO}_{2}$ could improve enzyme activity and stability by solubilization and removal of many impurities like carbohydrates, fatty acids, and triglycerides that can be present in free enzyme preparations while the enzyme is generally insoluble in $\mathrm{SC}-\mathrm{CO}_{2}$ [15]. To evaluate this effect, protein concentration was determined by the Bradford method [19], finding that protein concentration was not significantly affected $(p<0.05)$ by the $\mathrm{SC}-\mathrm{CO}_{2}$ treatment in any of the experiences performed with both free enzyme preparations. These results were expected since water solubility in $\mathrm{SC}-\mathrm{CO}_{2}$ is low at the pressure and temperature 
conditions assayed in this work and also because it was assumed that commercial enzyme preparations were subjected to several purification steps during their production processes.

It has been also proposed that $\mathrm{SC}-\mathrm{CO}_{2}$ may interact with hydrophobic tryptophan (Trp) and tyrosine (Tyr) residues in the enzyme structure during the treatment [10-14]. Liu et al [11] proposed that, below a pressure threshold that depends on the enzyme nature and on the experimental conditions, $\mathrm{CO}_{2}$ can interact with Trp and Tyr residues by means of weak interactions, promoting conformational changes that lead to a more accessible active site. However, above this threshold value, $\mathrm{CO}_{2}$ interacts mainly chemically with these amino acids, affecting negatively the free enzyme activity [11]. This hypothesis could explain the activity enhancement observed at mild conditions for both free lipases and the activity loss at the highest pressure and the longest exposure time in this study. The operating pressure threshold for both free lipases studied in this work is about 150 bar. A similar value was found in the studies of the stability of soluble Candida rugosa Lip7 after sub/SC-CO ${ }_{2}$ exposure [11].

\subsubsection{Conformational changes. Fluorescence emission spectra}

The hypothesis of $\mathrm{SC}-\mathrm{CO}_{2}$ induced conformational and activity changes has been studied by measuring the fluorescence emission spectra of some experiments of both free lipases before and after $\mathrm{SC}-\mathrm{CO}_{2}$ treatment at different experimental conditions. Fluorescence spectroscopy is an available technique for studying the conformational structure of free enzymes, in which the intrinsic fluorescence at $280 \mathrm{~nm}$ of Trp and Tyr residues is influenced by the environment [20]. Therefore, differences in the intrinsic fluorescence intensity can indicate changes in the tertiary structure of the lipases. 
Results are presented in Figure 3. From this figure, it can be observed that the fluorescence emission spectra of the $\mathrm{SC}-\mathrm{CO}_{2}$ treated samples and their respective untreated samples are significantly different, indicating that interactions between SC$\mathrm{CO}_{2}$ and Trp and Tyr residues have occurred and thus their microenvironments were significantly altered. Samples from experiences 2 and 4 from Palatase $20000 \mathrm{~L}$ and experience 4 from Lipozyme CALB L showed higher fluorescence intensity maxima when compared to their respective untreated samples, indicating that the $\mathrm{SC}-\mathrm{CO}_{2}$ treatment had led the enzyme to adopt an open conformation in which the lid moves to uncover the active site [21]. In these conditions, enzyme substrates could easily reach the active site and the enzyme activity would be enhanced, as it was observed in the residual activity determinations (Table 1 and Figs. 2 a,b,c).

On the other hand, samples from experiences 5 and 7 of both free enzymes showed lower fluorescence intensity maxima, which is in coincidence with a relatively low residual activity (Table 1 and Fig. 2 a,b,c). It seems that $\mathrm{SC}-\mathrm{CO}_{2}$ treatment at these conditions could have induced irreversible changes leading to an unfolded conformation in which Trp and Tyr residues have been transferred to a more hydrophobic environment. As it has been previously explained in section 3.1.1, some authors have suggested that, when a pressure threshold is reached [11], the interactions between SC$\mathrm{CO}_{2}$ and Trp and Tyr residues become stronger, affecting negatively the free enzyme activity.

As depicted in Figure 3, the regression of the fluorescence intensity maxima of each sample versus their respective residual activity showed a linear dependence between these two parameters. The higher the fluorescence intensity maximum, the higher the residual activity. Chen et al. [13], with Candida rugosa lipase, Psedomonas fluorescens 
lipase and Rhizopus oryzae lipase treated with sub/SC-CO $\mathrm{CO}_{2}$ observed an initial increase of the residual activity with the fluorescence intensity maxima was found, but then a decrease of fluorescence occurred and samples with higher residual activity showed lower fluorescence intensity maxima [13].

\subsection{Immobilized enzymes}

\subsubsection{Residual activity}

The experimental results obtained in the residual activity determination of the immobilized enzymes are presented in Table 1 and Figure 2 a-d. In general, it can be seen that $\mathrm{SC}-\mathrm{CO}_{2}$ treatment led to activity losses in all the experiments performed, except for Lipozyme RM IM in experience 1, in which no significant effect of SC-CO treatment in the residual activity was observed.

It must be highlighted that lipase from Rhizomucor miehei either in its free (Palatase $20000 \mathrm{~L}$ ) or in its immobilized form (Lipozyme RM IM) is more stable under the conditions assayed in this work than lipase B from Candida antartica in its free (CALB) or immobilized form (Lipozyme 435) exposed to the same conditions. Some authors [22] reported that the enzyme stability under $\mathrm{SC}-\mathrm{CO}_{2}$ could be related to the number of disulfide bonds that are present in the protein structure; however, both lipases have three disulfide bonds that stabilize the molecule [22,23].

Due to the relatively moderate pressure applied in most $\mathrm{SC}-\mathrm{CO}_{2}$ processes, the direct effect of pressure on enzyme inactivation can be considered small [3] and they may exist indirect effects that lead to activity losses on the immobilized enzymes. In literature, it has been proposed that interactions between lipase amino groups and $\mathrm{CO}_{2}$ can promote the formation of carbamates that contribute to the loss of enzyme activity 
[24]. Local change of $\mathrm{pH}$ has been also suggested due to absorption of $\mathrm{CO}_{2}$ into the hydrated areas of the lipase [3,25]. However, Kamat et al. [26] proposed that pH changes were not the main reason for lowering enzyme activity, but the rapid release of $\mathrm{CO}_{2}$ dissolved in the bound water of the enzyme and pressurization/depressurization cycles could be responsible by means of structural changes in the enzyme, resulting in its inactivation.

As in the case of free enzymes, the highest activity losses (23.5 \% for Lipozyme RM IM and $26.2 \%$ for Lipozyme 435) were found at the highest temperature studied in this work ( $70^{\circ} \mathrm{C}$, experience 5$)$. To check the effect of temperature in the residual activity of the immobilized enzymes after exposure to conventional organic solvents, experience 5a was conducted at $70{ }^{\circ} \mathrm{C}$, atmospheric pressure and n-heptane as reaction media (Table 1). Results obtained showed lower residual activity, indicating a protective effect of SC- $\mathrm{CO}_{2}$ media in the enzyme thermostability.

For immobilized lipases, the effect of pressurization/depressurization cycles has been also studied since it is an important operating parameter in batch or packed bioreactors. Both immobilized lipases were exposed up to three pressurization/depressurization cycles at $50^{\circ} \mathrm{C}$ for $180 \mathrm{~min}$. A slightly decrease in lipase activity has been found by increasing the number of pressurization/depressurization cycles from 1 to 3 (from 92.1 to $88.1 \%$ initial activity for Lipozyme RM IM and from 82.2 to $78.8 \%$ initial activity for Lipozyme 435). These results are in agreement with Marty et al. [27] that reported activity loss in the lipase from Mucor miehei treated with hydrated SC- $\mathrm{CO}_{2}$ and no further activity loss in successive depressurizations using dry SC-CO $\mathrm{CO}_{2}$ It has been also reported that hydrolases with disulfide bonds have a lower degree of inactivation after several pressurization/depressurization cycles that enzymes without them [28]. 
In this study, longer exposure times had greater negative effect on enzyme activity than the number of pressurization/depressurization cycles: for 60 min the activity loss was $5.6 \%$ and $11.8 \%$ for Lipozyme RM IM and Lipozyme 435 respectively while for 360 min the activity loss increased up to $12.6 \%$ and $20.3 \%$ for Lipozyme RM IM and Lipozyme 435, respectively. In general, these activity losses could be attributed to the negative interactions that have been explained before, although extended in a longer period of time. Lanza et al. [29] and Oliveira et al. [6] also found a negative influence of the exposure time on the residual activity of Novozym 435 [6,29] and Lipozyme IM [6] after SC- $\mathrm{CO}_{2}$ treatment in the same range of exposure times $(60-360 \mathrm{~min})$ and similar pressure and temperature conditions $\left(40-70{ }^{\circ} \mathrm{C}\right.$; $80.0-255.5$ bar [28] and $35-75{ }^{\circ} \mathrm{C}$; 71.5 - 276.4 bar [6]).

\subsubsection{Effect of water content on the residual activity}

As it has been explained, the enzyme activity loss after $\mathrm{SC}-\mathrm{CO}_{2}$ exposure depends on several parameters. One of the most important is the amount of water needed to maintain their native conformation and hence, their functionality. During exposure to SC- $\mathrm{CO}_{2}$ essential water of the enzyme can be solubilized into the $\mathrm{SC}-\mathrm{CO}_{2}$ (0.3 to $0.5 \mathrm{~g}$ water/100 $\mathrm{g} \mathrm{CO}_{2}$, depending on operating pressure and temperature [7]). During the depressurization step, $\mathrm{CO}_{2}$ is released and the solubilized water is removed from the enzyme preparation. For the experiments performed with Lipozyme RM IM, titrable water was determined by Karl-Fischer before and after $\mathrm{SC}-\mathrm{CO}_{2}$ exposure. Figure 4 shows the relationship between Lipozyme RM IM residual activity and the water loss regarding the initial water content. Experience 5 was excluded because the high activity loss could be mainly atributted to thermal inactivation. From the graph in Figure 4, a 
correlation can be observed between the loss of water after $\mathrm{SC}-\mathrm{CO}_{2}$ exposure and Lipozyme RM IM activity loss when deppresurization cycles were not performed. It must be pointed out that the greatest loss of water from the enzyme took place after several pressurization/depressurization cycles (experiences 8 and 9), although these water losses did not result in further activity losses.

For Lipozyme 435 the initial titrable water content was determined ( $0.7 \pm 0.2 \mathrm{~g} / 100 \mathrm{~g})$. However, water measurements were not reliable after $\mathrm{SC}-\mathrm{CO}_{2}$ exposure due to the very low values found and not a clear correlation could be established between water and activity losses. In any case, it must be emphasized that in the literature it has been reported that lipase B from C. antarctica (CALB), of which Lipozyme 435 is an immobilized form, is a less water-sensitive lipase than others, either in its free or immobilized form [30]. Immobilized CALB dehydrated by dry ethanol was still able to retain active conformation, suggesting that essential water molecules are kept in its structure [30]. However, activity losses have been found after $\mathrm{SC}-\mathrm{CO}_{2}$ treatment in this study. It could be possible that $\mathrm{CO}_{2}$ molecules could enter inside the CALB active site, which is an elliptical and steep funnel, stripping out the essential water molecules due to its better transport properties compared to conventional solvents, such as ethanol. But it is also possible that conformational changes happened during $\mathrm{SC}-\mathrm{CO}_{2}$ exposure and in the pressurization and/or depressurization cycles, affecting negatively Lipozyme 435 activity [6,31,32].

To study the effect of water removal by $\mathrm{SC}-\mathrm{CO}_{2}$, another set of residual activity determinations was carried out after adding different amounts of water to the reaction media (from 0 to $16 \%$ wt. based on enzyme). Results obtained (Fig. 5) showed that Lipozyme RM IM was able to recover its initial activity when a low amount of water 
was added (around $0.5-1 \%$ wt. based on enzyme). This behavior was not observed on Lipozyme 435. The enzyme support of Lipozyme RM IM is hydrophilic and some water can be easily adsorbed; however, the hydrophobic character of the immobilization support of Lipozyme 435 might not allow the enzyme to recover its constitution water, showing an initial plateau. In both enzymes, larger amounts of added water resulted in the decrease of the enzymatic activity. Since water is a reaction product, it can be assumed that this excess of free water could slow down the reaction rate. Conformational changes could also take place at high water concentrations [33] and, in the case of Lipozyme RM IM, mass transfer limitations could have occurred due to water adsorption on the hydrophilic immobilization support.

\subsubsection{Conformational and morphological changes}

The conformational and morphological structures of $\mathrm{SC}-\mathrm{CO}_{2}$-treated and untreated immobilized lipases were also investigated by FT-IR and SEM, respectively.

\section{Infrared spectra}

FT-IR analysis of the untreated and SC- $\mathrm{CO}_{2}$-treated immobilized lipases was performed in the range between 4000 and $400 \mathrm{~cm}^{-1}$ (Fig. 6). In the protein FT-IR spectra, the major protein absorption bands due to the peptide group vibrations occur between 1900 and $1200 \mathrm{~cm}^{-1}$ [34]. Different bands can be observed in this region: the amide I band (between 1700 and $1600 \mathrm{~cm}^{-1}$ ) is mainly associated with carbonyl stretching of the peptide. It consists of a group of overlapped signals, providing information about the secondary protein structure of the enzyme; the amide II band $\left(1580-1510 \mathrm{~cm}^{-1}\right)$ is due to the $\mathrm{N}-\mathrm{H}$ bending with a contribution of the C-N stretching vibrations and the amide III region (1400-1200 $\left.\mathrm{cm}^{-1}\right)$, which has a weaker intensity [34,35]. Therefore, the spectra 
data between 1800 and $1500 \mathrm{~cm}^{-1}$ were taken and plotted in further detail after baseline correction and normalization. It was found that there was no significant difference between the spectra of the untreated immobilized lipases and the spectra of the ones exposed to $\mathrm{SC}-\mathrm{CO}_{2}$. These results are in coincidence with the works by Oliveira et al. [6] and Jenab et al. [17] and, based on them, no significant conformational changes in the secondary structure of the immobilized lipases were observed after enzyme treatment with SC-CO 2 .

Scanning Electron Microscopy (SEM)

Scanning Electron Microscopy (SEM) was used to investigate any potential morphological changes in both immobilized lipases. Micrographs from Lipozyme RM IM and Lipozyme 435 are shown in Figures 7 and 8, respectively. Immobilization support of Lipozyme RM IM was also studied (Fig. 7d).

Some authors reported that $\mathrm{SC}-\mathrm{CO}_{2}$ can interact with the enzyme support, resulting in deformations such as plasticization and swelling [36]. In some cases, rapid depressurization can lead to the formation of cracks and holes in the support surface and increased porosity [6]. Recently, Jenab et al. [17] have observed structural changes in the SEM micrographs of Lipozyme RM IM and Lipozyme TL IM after SC-CO ${ }_{2}$ treatment. Nevertheless, it was concluded that such changes could be attributed to mechanical stresses caused by magnetic stirring during $\mathrm{SC}-\mathrm{CO}_{2}$ exposure and not to pressurization/depressurization cycles [17]. In this study, external orbital agitation was used in the SC- $\mathrm{CO}_{2}$ treatment of the immobilized enzymes instead of internal magnetic stirring; therefore, the support was not subjected to intense mechanical stresses due to that means of stirring. However, rapid depressurization (240 $\mathrm{kg} \mathrm{CO}_{2} \mathrm{~m}^{-3} \mathrm{~min}^{-1}$ ), and several depressurization cycles were conducted. As a consequence, a rough and cracked 
surface with an apparent increase of porosity can be appreciated after $\mathrm{SC}-\mathrm{CO}_{2}$ treatment in 10,000x magnifications of Figs. 7 b,c and 8 b,c.

\section{Conclusions}

In the present work, four commercial lipases: free Palatase $20000 \mathrm{~L}$ and Lipozyme CALB L, and immobilized Lipozyme RM IM and Lipozyme 435, were subjected to SC$\mathrm{CO}_{2}$ treatment. Based on the results obtained, it can be concluded that $\mathrm{SC}-\mathrm{CO}_{2}$ treatment at the experimental conditions in this study can affect the enzyme activity by means of conformational changes and structural alterations. It is also important to notice that the effect of the $\mathrm{SC}-\mathrm{CO}_{2}$ treatment strongly depends on the experimental conditions, the nature and the source of the enzyme and, mainly, whether the enzyme is presented in a free or immobilized form. In the case of immobilized enzymes, the characteristics of the support should be also taken into account.

The results obtained in this work may help with the purpose of selecting the most appropriate operation conditions at the typical reactions conducted in the biotransformation of lipids under SC- $\mathrm{CO}_{2}$, with the lowest activity loss, or, when possible, the highest activity improvement.

\section{Acknowledgments}

To the Spanish Government through MINECO and the European Regional Development Fund (ERDF) for financial support to the project CTQ2012-39131-C0201. To Novozymes A/S for kindly supplying the enzymes. RM acknowledges MINECO for a predoctoral grant (reference BES-2013-063937). SLB acknowledges Mexican Secretariat of Public Education and Technological University of Morelia for a 
fellowship through PROMEP program. AGS acknowledges University of Burgos for a fellowship.

\section{References}

[1] K.-E. Jaeger, T. Eggert, Lipases for Biotechnology, Current Opinion in Biotechnology 13 (2002) 390-397.

[2] A. Zaks, A.M. Klibanov, Enzyme-catalyzed processes in organic solvents, Proceedings of the National Academy of Sciences of the United States of America 82 (1985) 3192-3196.

[3] K. Nakamura, Biochemical reactions in supercritical fluids, TibTech 8 (1990) 288-292.

[4] M.C. Almeida, R. Ruivo, C. Maia, L. Freire, T. Corrêa de Sampaio, S. Barreiros, Novozym 435 activity in compressed gases. Water activity and temperature effects, Enzyme and Microbial Technology 22 (1998) 494-499.

[5] G. Bell, P.J. Halling, B.D. Moore, J. Partridge, D.G. Rees, Biocatalyst behaviour in low-water systems, Trends in Biotechnology 13 (1995) 468-473.

[6] D. Oliveira, A.C. Feihrmann, A.F.Rubira, M.H. Kunita, C. Dariva, J.V. Oliveira, Assessment of two immobilized lipases activity treated in compressed fluids, J. Supercritical Fluids 38 (2006) 373-382.

[7] Z. Wimmer, M. Zarevúcka, A review on the effects of supercritical carbon dioxide on enzyme activity, International J. Molecular Sciences 11 (2010) 233-253.

[8] S. Damar, M.O. Balaban, Review of dense phase $\mathrm{CO}_{2}$ technology: microbial and enzyme inactivation and effects on food quality, J. Food Science 71 (2006) 1-11. 
[9] D. Senyay-Oncel, O. Yesil-Celiktas, Activity and stability enhancement of $\alpha$ amylase treated with sub- and supercritical carbon dioxide, J. Bioscience and Bioengineering 112 (2011) 435-440.

[10] S. Pan, X. Liu, Y. Xie, Y. Yi, C. Li, Y. Yan, Y. Liu, Esterification activity and conformation studies of Burkholderia cepacia lipase in conventional organic solvents, ionic liquids and their co-solvent mixture media, Bioresource Technology 101 (2010) 9822-9824.

[11] Y. Liu, D. Chen, L. Xu, Y. Yan, Evaluation of structure and hydrolysis activity of Candida rugosa Lip7 in presence of sub-/super-critical $\mathrm{CO}_{2}$, Enzyme and Microbial Technology 51 (2012) 354-358.

[12] Y. Liu, D. Chen, S. Wang, Effect of sub- and super-critical $\mathrm{CO}_{2}$ pretreatment on conformation and catalytic properties evaluation of two commercial enzymes of CALB and Lipase PS, J. Chemical Technology and Biotechnology 88 (2013) 1750-1756.

[13] D. Chen, C. Peng, H. Zhang, Y. Yan, Assessment of activities and conformation of lipases treated with sub- and supercritical carbon dioxide, Applied Biochemistry and Biotechnology 169 (2013) 2189-2201.

[14] D. Chen, H. Zhang, J. Xu, Y. Yan, Effect of sub- and supercritical $\mathrm{CO}_{2}$ treatment on the properties of Pseudomonas cepacia lipase, Enzyme and Microbial Technology 53 (2013) 110-117.

[15] A. Gießauf, T. Gamse, A simple process for increasing the specific activity of porcine pancreatic lipase by supercritical carbon dioxide treatment, J. Molecular Catalysis B: Enzymatic 9 (2000) 57-64. 
[16] E. Séverac, O. Galy, F. Turon, P. Monsan, A. Marty, Continuous lipasecatalyzed production of esters from crude high-oleic sunflower oil, Bioresource Technology 102 (2011) 4954-4961.

[17] E. Jenab, F. Temelli, J.M. Curtis, Y.-Y. Zhao, Performance of two immobilized lipases for interesterification between canola oil and fully-hydrogenated canola oil under supercritical carbon dioxide, LWT - Food Science and Technology 58 (2014) 263-271.

[18] C. Bauer, D.-J. Steinberger, G. Schlauer, T. Gamse, R. Marr, Activation and denaturation of hydrolases in dry and humid supercritical carbon dioxide (SC-CO 2$), \mathrm{J}$. Supercritical Fluids 19 (2000) 79-86.

[19] M.M. Bradford, A rapid and sensitive method for the quantitation of microgram quantities of protein utilizing the principle of protein dye binding, Analytical Biochemistry 72 (1976) 248-254.

[20] J.R. Lakowicz, Principles of fluorescence spectroscopy, 3rd ed., Springer Science+Business Media, LLC, New York, 2006, pp.63-94.

[21] M. Habulin, Ž. Knez, Activity and stability of lipases from different sources in supercritical carbon dioxide and near-critical propane, J. Chemical Technology and Biotechnology 76 (2001) 1260-1266.

[22] M. Arroyo, J.M. Sánchez-Montero, J.V. Sinisterra, Thermal stabilization of immobilized lipase B from Candida antarctica on different supports: Effect of water activity on enzymatic activity in organic media, Enzyme and Microbial Technology 24 (1999) 3-12. 
[23] R.C. Rodrigues, R. Fernandez-Lafuente, Enzymatic Lipase from Rhizomucor miehei as a biocatalyst in fats and oils modification, J. Molecular Catalysis B: Enzymatic 66 (2010) 15-32.

[24] S.V. Kamat, G. Critchley, E.J. Beckman, A.J. Russell, Biocatalytic synthesis of acrylates in organic solvents and supercritical fluids: III. Does carbon dioxide covalently modify enzymes?, Biotechnology and Bioengineering 46 (1995) 610-620.

[25] F. Kao, S.A. Ekhorutomwen, S.P. Sawan, Residual stability of lipase from Candida rugosa in hexane, supercritical $\mathrm{CO}_{2}$, and supercritical $\mathrm{SF}_{6}$, Biotechnology Techniques 11 (1997) 849-852.

[26] S. V. Kamat, E.J. Beckman, A.J. Russell, Enzyme activity in supercritical fluids, Critical Reviews in Biotechnology 15 (1995) 41-71.

[27] A. Marty, W. Chulalaksananukul, J.S. Condoret, R.M. Willemot, G. Durand, Comparison of lipase-catalysed esterification in supercritical carbon dioxide and in nhexane, Biotechnology Letters 12 (1990) 11-16.

[28] A. Gießauf, W. Magor, D.J. Steinberger, R. Marr, A study of hydrolases stability in supercritical carbon dioxide (SC-CO 2 ), Enzyme and Microbial Technology 24 (1999) 577-583.

[29] M. Lanza, W.L. Priamo, J.V. Oliveira, C. Dariva, D. Oliveira, The effect of temperature, pressure, exposure time, and depressurization rate on lipase activity in SCCO 2 , Applied Biochemistry and Biotechnology 113 (2004) 181-187.

[30] W. Piyatheerawong, Y. Iwasaki, X. Xu, T. Yamane, Dependency of water concentration on ethanolysis of trioleoylglycerol by lipases, J. Molecular Catalysis B: Enzymatic. 28 (2004) 19-24. 
[31] M.G. Aucoin, R.L. Legge, Effects of supercritical $\mathrm{CO}_{2}$ exposure and depressurization on immobilized lipase activity, Biotechnology Letters 23 (2001) 18631870.

[32] J. Zagrobelny, F. V Bright, In situ studies of protein conformation in supercritical fluids: trypsin in carbon dioxide, Biotechnology Progress 8 (1992) 421423.

[33] Ž. Knez, Enzymatic reactions in dense gases, J. Supercritical Fluids 47 (2009) 357-372.

[34] A. Natalello, D. Ami, S. Brocca, M. Lotti, S.M. Doglia, Secondary structure , conformational stability and glycosylation of a recombinant Candida rugosa lipase studied by Fourier-transform infrared spectroscopy, Biochemical J. 517 (2005) 511-517. [35] S.E. Collins, V. Lassalle, M.L. Ferreira, FTIR-ATR characterization of free Rhizomucor meihei lipase (RML), Lipozyme RM IM and chitosan-immobilized RML, J. Molecular Catalysis B: Enzymatic 72 (2011) 220-228.

[36] M. Habulin, M. Primožič, Ž. Knez, Supercritical fluids as solvents for enzymatic reactions, Acta Chimica Slovenica 54 (2007) 667-677. 


\section{Figure captions}

Fig. 1. Experimental apparatus for enzyme treatment with $\mathrm{SC}-\mathrm{CO}_{2}$. 1: $\mathrm{CO}_{2}$ cylinder; 2: syringe pump; 3: rupture disk; 4: vent valve; 5: process valve; 6: general pressure gauge; 7: general inlet valve; 8: individual inlet valve; 9: high pressure cell; 10: thermostatic water bath; 11: magnetic stirrer; 12: external orbital agitation; 13: individual pressure gauge; 14: depressurization valve; 15: total flow-meter.

Fig. 2. Effect of the experimental conditions of the $\mathrm{SC}-\mathrm{CO}_{2}$ treatment on the residual activity of the studied lipases. a) Effect of pressure (100 - 250 bar: exp1-exp3); b) Effect of temperature (35 - $70^{\circ} \mathrm{C}$ : $\exp 2$, exp4 and exp5); c) Effect of exposure time (60 - 360 min: exp6, exp2 and exp7); d) Effect of depressurization cycles (1 - 3: exp 2, exp8 and exp9). Lines are drawn to guide the eye.

Fig. 3. Fluorescence emission spectra of the studied free lipases before and after SC$\mathrm{CO}_{2}$ treatment under different experimental conditions.

Fig. 4. Lipozyme RM IM residual activity versus water content after $\mathrm{SC}-\mathrm{CO}_{2}$ treatment. Numbers indicate established conditions in each experiment (see Table 1).

Fig. 5. Residual activities of the studied immobilized lipases after $\mathrm{SC}-\mathrm{CO}_{2}$ treatment and different amounts of water added. Empty symbols: untreated samples; full squares: treated samples from exp.2. Dashed lines indicate the residual activity value of each treated lipase (exp. 2) when no water was added.

Fig. 6. FT-IR spectra of the studied immobilized lipases before and after SC-CO2 treatment. Left: complete IR spectra $(4000-400 \mathrm{~cm}-1)$; right: detail of the 1800 $1500 \mathrm{~cm}^{-1}$ region. Treated samples from exp. 2 . 
Fig. 7. SEM micrographs of Lipozyme RM IM. Left to right: $50 \mathrm{x}, 600 \mathrm{x}$ and 10,000 x. (a) untreated enzyme; (b) treated sample from exp. 3; (c) treated sample from exp. 9; (d) immobilization support alone (Duolite A568).

Fig. 8. SEM micrographs of Lipozyme 435. Left to right: $50 \mathrm{x}, 600 \mathrm{x}$ and 10,000 x. (a) untreated enzyme; (b) treated sample from exp. 3; (c) treated sample from exp. 9. 
Table 1 Residual activities (\% of initial activity) observed in the four commercial enzymes after SC-CO 2 treatment at the established conditions in each experiment.

\begin{tabular}{|c|c|c|c|c|c|c|c|c|}
\hline \multirow[b]{2}{*}{ exp. } & \multicolumn{4}{|c|}{ Experimental conditions } & \multicolumn{4}{|c|}{ Residual activity (\% of initial activity) } \\
\hline & $\begin{array}{c}\mathbf{p} \\
\text { (bar) }\end{array}$ & $\begin{array}{c}\mathrm{T} \\
\left({ }^{\circ} \mathrm{C}\right)\end{array}$ & $\begin{array}{c}t \\
(\min )\end{array}$ & $\begin{array}{c}\text { dep. } \\
\text { cycles }\end{array}$ & $\begin{array}{l}\text { Palatase } \\
20000 \text { L }\end{array}$ & $\begin{array}{l}\text { Lipozyme } \\
\text { CALB L }\end{array}$ & $\begin{array}{c}\text { Lipozyme } \\
\text { RM IM }\end{array}$ & $\begin{array}{c}\text { Lipozyme } \\
435\end{array}$ \\
\hline 1 & 100 & & & & $126.0 \pm 1.6$ & $104.1 \pm 1.9$ & $100.2 \pm 1.1$ & $96.5 \pm 2.2$ \\
\hline 2 & 150 & 50 & 180 & 1 & $121.1 \pm 3.5$ & $107.5 \pm 0.6$ & $92.1 \pm 2.2$ & $82.2 \pm 1.5$ \\
\hline 3 & 250 & & & & $96.1 \pm 3.1$ & $97.3 \pm 0.8$ & $89.2 \pm 1.2$ & $86.2 \pm 2.4$ \\
\hline 4 & 150 & 35 & 100 & 1 & $134.1 \pm 1.9$ & $112.3 \pm 1.3$ & $96.0 \pm 0.6$ & $95.1 \pm 1.1$ \\
\hline 5 & 150 & 70 & 100 & 1 & $86.3 \pm 2.8$ & $80.9 \pm 0.9$ & $76.5 \pm 1.5$ & $73.8 \pm 1.6$ \\
\hline $5 a^{*}$ & atm & 70 & 180 & 1 & - & - & $68.9 \pm 1.8$ & $63.3 \pm 2.2$ \\
\hline 6 & 150 & 50 & 60 & 1 & $134.8 \pm 1.7$ & $109.6 \pm 1.5$ & $94.4 \pm 1.4$ & $89.2 \pm 0.7$ \\
\hline 7 & 100 & 50 & 360 & 1 & $111.9 \pm 2.5$ & $96.2 \pm 1.2$ & $87.4 \pm 0.3$ & $79.7 \pm 1.1$ \\
\hline 8 & 150 & م & 10 & 2 & - & - & $91.6 \pm 0.4$ & $77.7 \pm 1.1$ \\
\hline 9 & & & & 3 & - & - & $88.1 \pm 2.7$ & $78.2 \pm 1.4$ \\
\hline
\end{tabular}




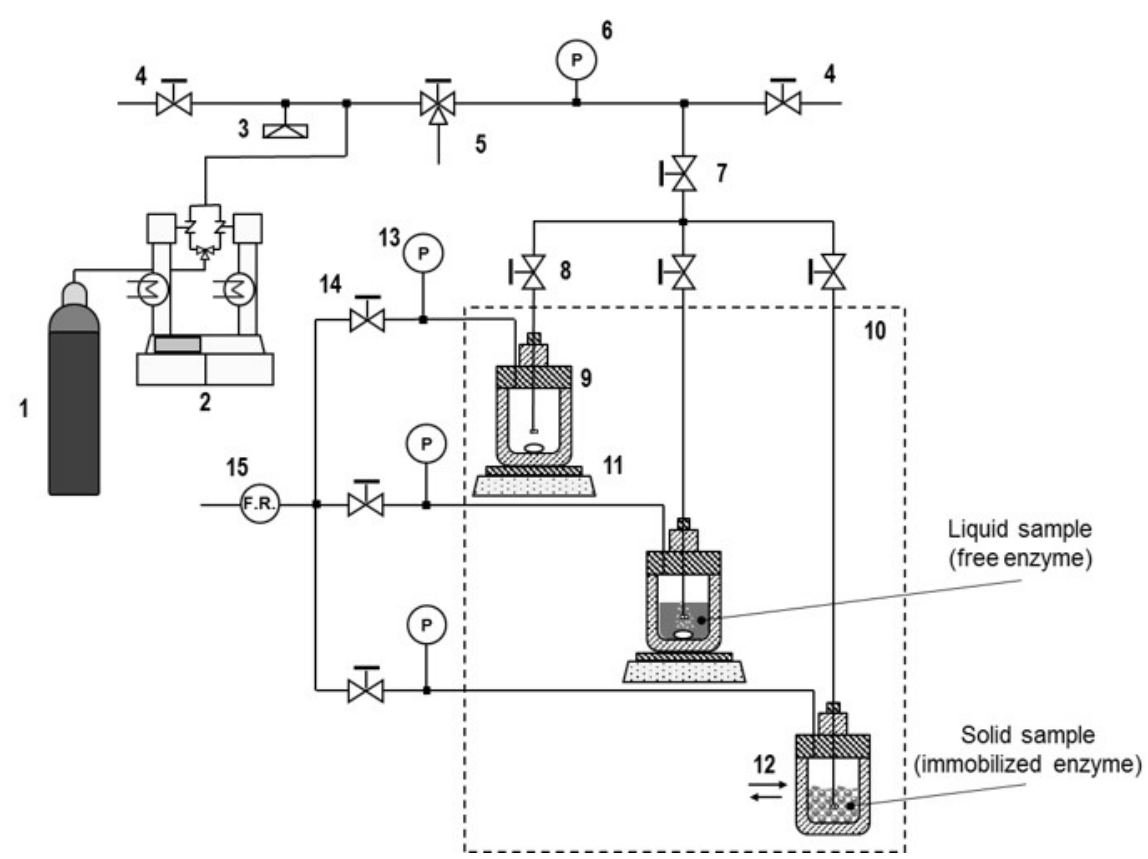

Fig. 1. Experimental apparatus for enzyme treatment with $\mathrm{SC}-\mathrm{CO}_{2} .1$ : $\mathrm{CO}_{2}$ cylinder; 2: syringe pump; 3: rupture disk; 4: vent valve; 5: process valve; 6: general pressure gauge; 7: general inlet valve; 8: individual inlet valve; 9: high pressure cell; 10: thermostatic water bath; 11: magnetic stirrer; 12: external orbital agitation; 13: individual pressure gauge; 14: depressurization valve; 15: total flow-meter. 

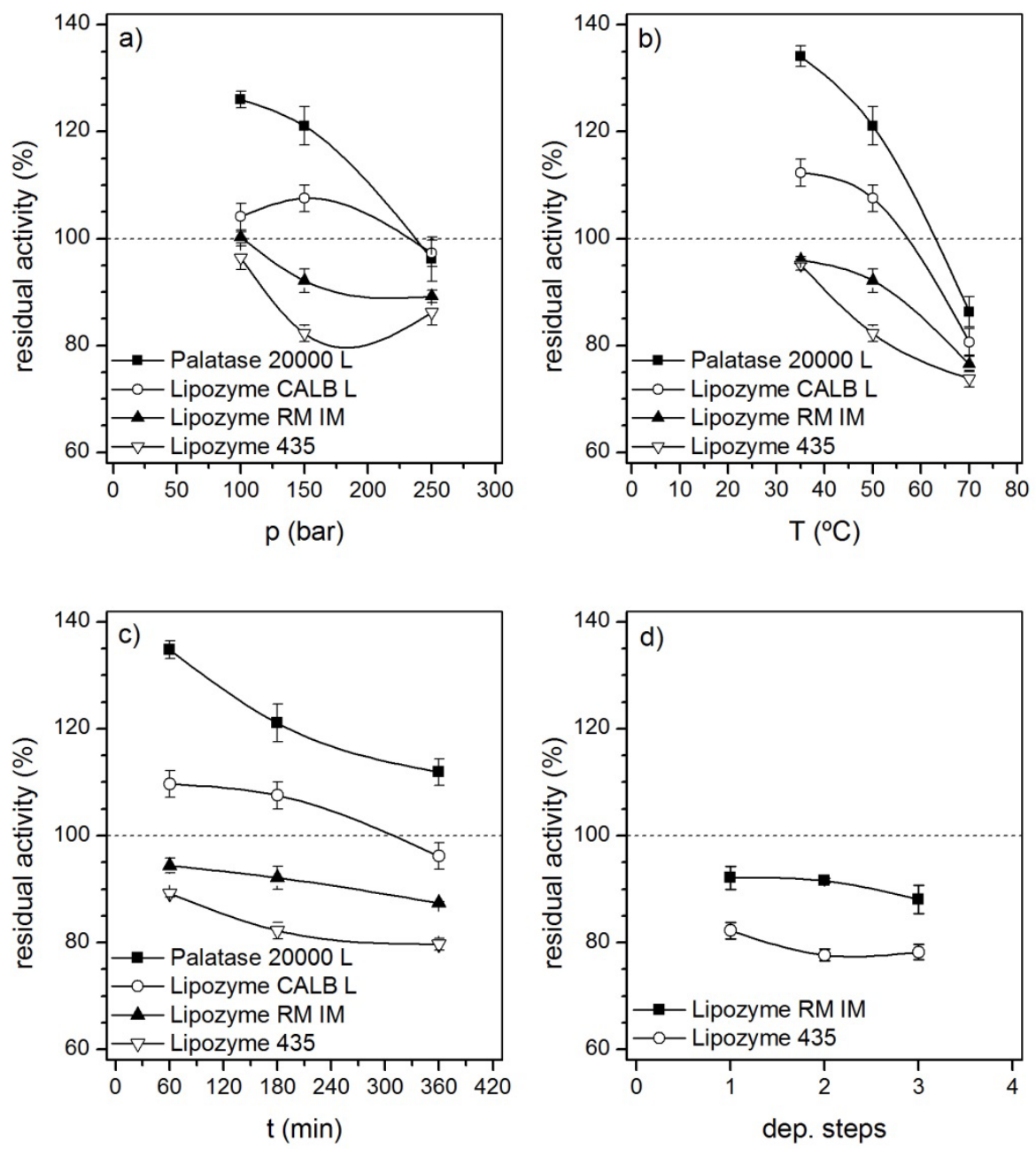

Fig. 2. Effect of the experimental conditions of the $\mathrm{SC}-\mathrm{CO}_{2}$ treatment on the residual activity of the studied lipases. a) Effect of pressure (100 - 250 bar: exp1-exp3); b) Effect of temperature (35 - $70^{\circ} \mathrm{C}$ : $\exp 2$, exp4 and exp5); c) Effect of exposure time (60 - 360 min: exp6, exp2 and exp7); d) Effect of depressurization cycles (1 - 3: exp 2, exp8 and exp9). Lines are drawn to guide the eye. 

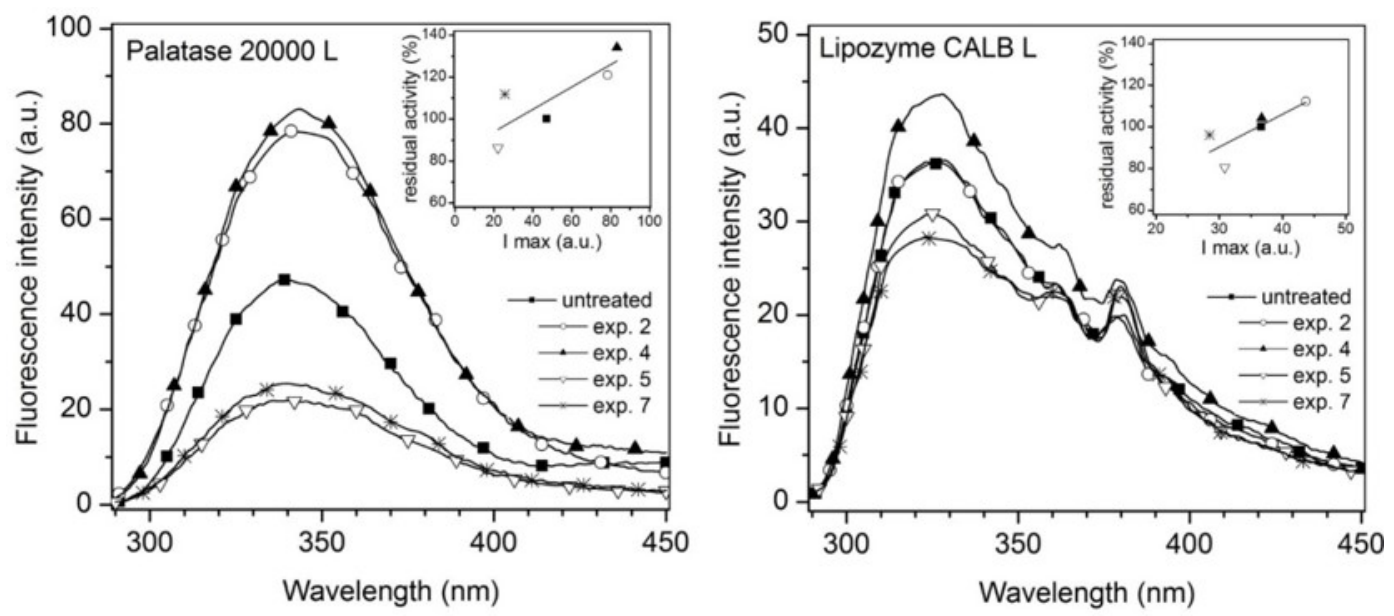

Fig. 3. Fluorescence emission spectra of the studied free lipases before and after SC$\mathrm{CO}_{2}$ treatment under different experimental conditions. 


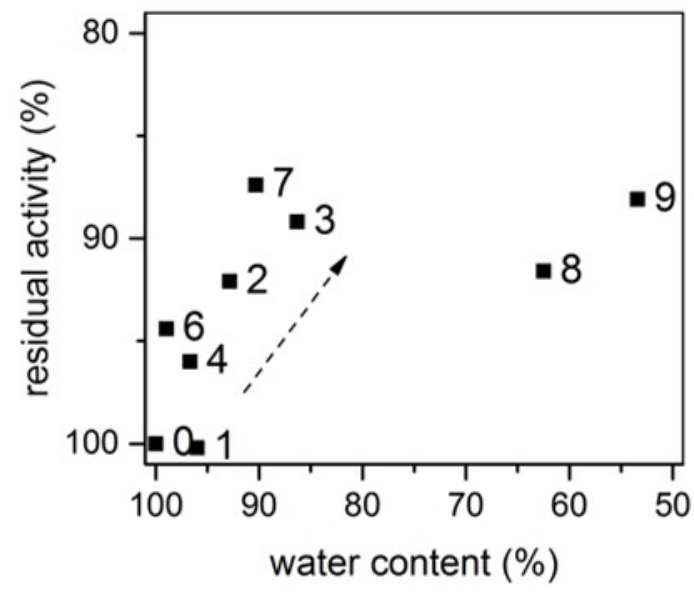

Fig. 4. Lipozyme RM IM residual activity versus water content after SC-CO $\mathrm{CO}_{2}$ treatment. Numbers indicate established conditions in each experiment (see Table 1). 


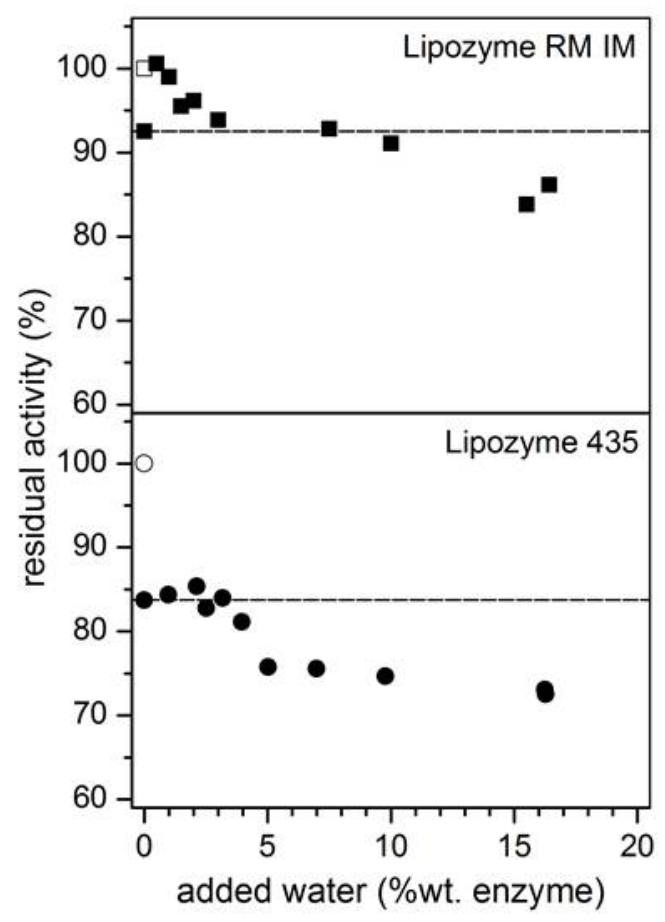

Fig. 5. Residual activities of the studied immobilized lipases after $\mathrm{SC}-\mathrm{CO}_{2}$ treatment and different amounts of water added. Empty symbols: untreated samples; full symbols: treated samples from exp.2. Dashed lines indicate the residual activity value of each treated lipase (exp. 2) when no water was added. 

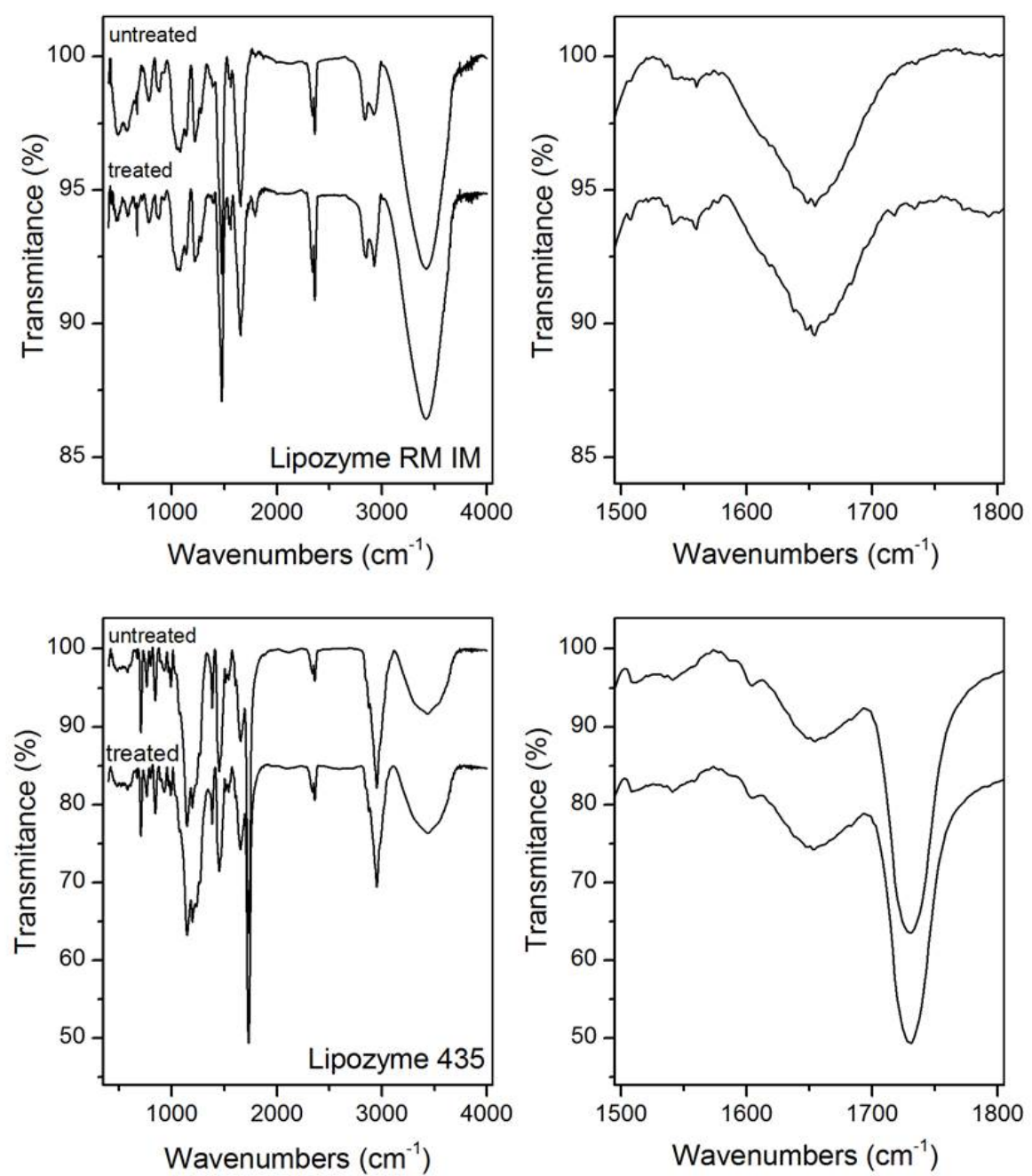

Fig. 6. FT-IR spectra of the studied immobilized lipases before and after $\mathrm{SC}-\mathrm{CO}_{2}$ treatment. Left: complete IR spectra $\left(4000-400 \mathrm{~cm}^{-1}\right)$; right: detail of the $1800-1500$ $\mathrm{cm}^{-1}$ region. Treated samples from exp. 2. 

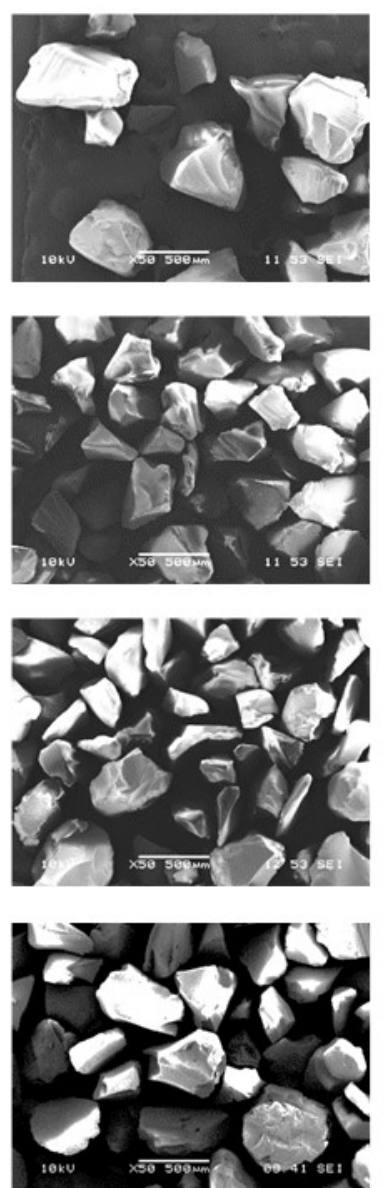

(a)

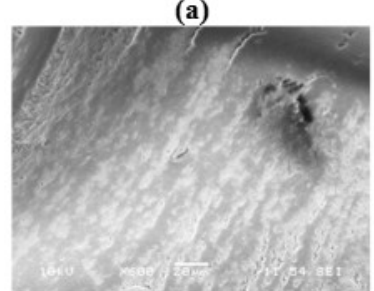

(b)

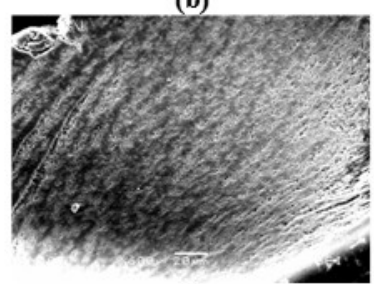

(c)

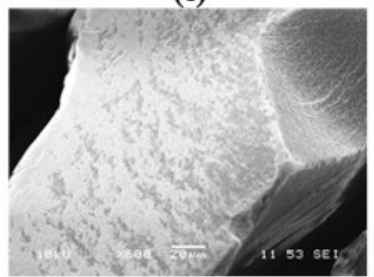

(d)

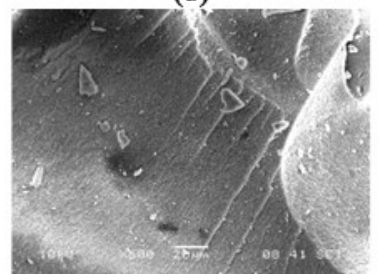

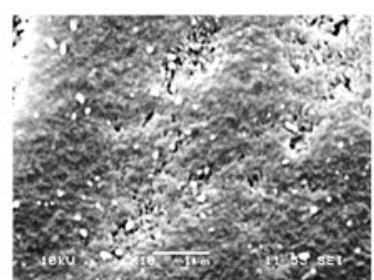
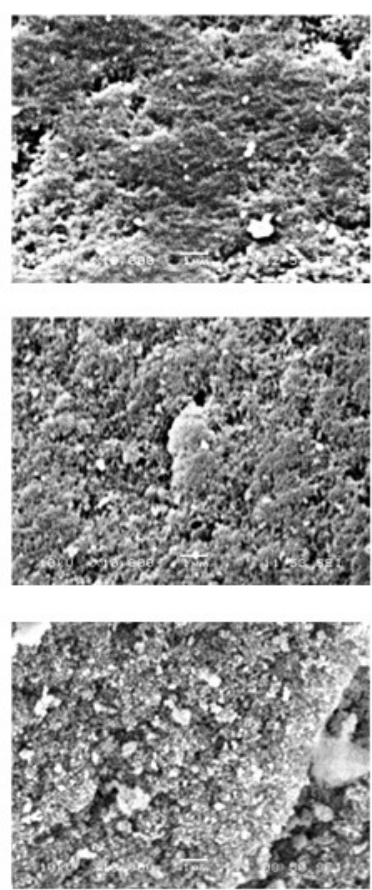

Fig. 7. SEM micrographs of Lipozyme RM IM. Left to right: $50 \mathrm{x}, 600 \mathrm{x}$ and 10,000 x.

(a) untreated enzyme; (b) treated sample from exp. 3; (c) treated sample from exp. 9; (d) immobilization support alone (Duolite A568). 

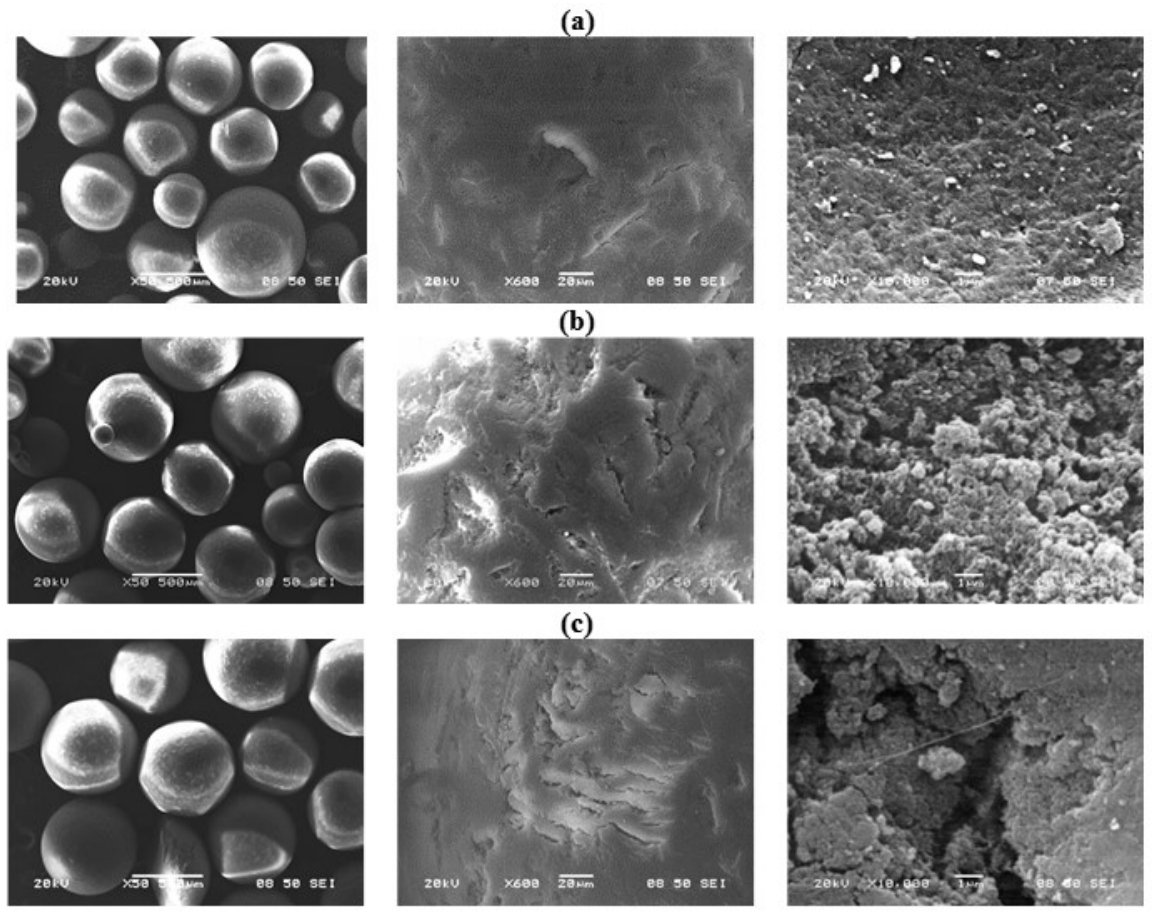

Fig. 8. SEM micrographs of Lipozyme 435. Left to right: $50 \mathrm{x}, 600 \mathrm{x}$ and 10,000 x. (a) untreated enzyme; (b) treated sample from exp. 3; (c) treated sample from exp. 9. 